\title{
A comparison of ARIMA and ANN techniques in predicting port productivity and berth effec- tiveness
}

\section{Desmond Eseoghene Ighravwe $^{\mathrm{a}^{*}}$ and Christopher Osita Anyaeche ${ }^{\mathrm{b}}$}

${ }^{a}$ Department of Mechanical and Biomedical Engineering, Bells University of Technology, Ota, Nigeria ${ }^{b}$ Department of Industrial and Production Engineering, University of Ibadan, Nigeria

\section{CH R O N I C L E}

Article history:

Received: October 2, 2018

Received in revised format: Octo-

ber 20,2018

Accepted: November 29, 2018

Available online:

November 30, 2018

Keywords:

ARIMA

Artificial neural network

Back-propagation algorithm

Berth effectiveness

Port productivity

\section{A B S T R A C T}

Business process evaluation is a common norm in small-medium-large industries globally and information obtained during such evaluation have been used in simulating the future performance of most industries using mathematical models such as Autoregressive Integrated Moving Average (ARIMA) and artificial neural network (ANN). This study explored the possibility of predicting port productivity and berth effectiveness of a seaport using ANN and ARIMA. A comparative analysis of a multi-layer perceptron (MLP) back propagation algorithm and ARIMA performance was carried out based on ships days at port, days at berth and tonnage: the model's input parameters, while port productivity and berth effectiveness were the model outputs. The MLP-ANN and ARIMA (1, 0, 4- port productivity) and (1, 0, 4-berth effectiveness) results were compared based on their coefficient of correlation and mean square error. The coefficient of correlation for port productivity prediction using MLP-ANN was 0.998 . This value outperformed that of ARIMA (0.9862) for port productivity; berth effectiveness coefficients of correlation of 0.9956 and 0.9928 were obtained using the MLP-ANN and the ARIMA models, respectively.

C 2019 by the authors; licensee Growing Science, Canada.

\begin{tabular}{|ll|}
\hline \multicolumn{2}{|l|}{ Nomenclatures } \\
$f_{i}$ & Outputs \\
$x_{i}$ & Inputs \\
$w_{i}$ & Connecting weight \\
$\alpha$ & Learning rate \\
$\theta_{i}$ & Bias \\
MSE & Mean square error \\
$G_{\max }$ & Maximum epoch \\
$R$ & Absolute fraction of variance \\
\hline
\end{tabular}

* Corresponding author.

E-mail address: ighravwedesmond@gmail.com (D. E. Ighravwe)

(C) 2019 by the authors; licensee Growing Science, Canada. doi: $10.5267 /$ j.ijdns.2018.11.003 


\section{Introduction}

For a business enterprise to remain competitive, her operation must be adequately evaluated and forecasted in order to effectively combine organisation's resources to yield desired goals. To achieve this, concepts such as productivity and system effectiveness have been applied in manufacturing and service industries (Stephens et al., 2012). These concepts enable the management of such systems to seek ways of improving her performances either through expansion or retention of their business scope. The issues of performance evaluation of service industry have attracted considerable attention in recent times from researchers and industrial practitioners with the hope of identifying the most appropriate measures for conducting system performance evaluation (Indraratna et al., 2011). A key performance measure which has gained wide acceptance in the service industries is productivity (Zemguliene, 2009). Combining productivity and system effectiveness will provide a broader picture of how well a system is managed.

This study is steered towards this direction with the aim of identifying a mathematical model that can be used to predict the performance of a sea port based on operational parameters. This is important in order to study the effects of combining different input parameters that are used in forecasting and monitoring sea port productivity and berth effectiveness, especially in developing economies such as Nigeria. From our literature search, sparse information on sea port productivity and berth effectiveness prediction have been documented. Thus, the focus of this paper is on service industries with an emphasis on shipping business in Nigeria.

In Nigeria, shipping business is a major contributor to her service industries outputs. Sea shores in Nigeria are dominated with several seaports, among which are ports of Apapa, Calabar, Escravos oil terminal, Warri, Koko and others (WPS, 2014). Nigeria depends on this mode of transportation for her crude oil importation and exportation. The revenue from crude oil contributes about $83 \%$ of Nigeria income in 2000 (Odularu, 2008).

Furthermore, other items for domestic and industrial purposes are shipped into Nigeria through some of these ports, particularly Apapa port in Lagos. Apapa port is the largest and most used seaports in Nigeria and sub-Sahara Africa because of its location, Lagos. The port's location has a significantly large number of manufacturing and non-manufacturing industries. The ships in this port are owned by local and foreign firms (Stephens et al., 2012). Due to the importance of Apapa, researchers have evaluated its performance in current times (Stephen et al., 2012; Nze, 2011). The study by Stephen et al (2012), Saari productivity model was applied in evaluating the productivity and berth effectiveness of Apapa port. Information on how to predict the port productivity and berth effectiveness was not reported in Stephen et al. (2012) study. This knowledge gap is among the motivations of this study.

Another motivation for this study is the lack of documentation on the application of artificial neural network (ANN) models (back-propagation ANN model) and Autoregression Integrated Moving Average (ARIMA) model in predicting port productivity and berth effectiveness. State-of-the-art of ANN in addressing wide range of management challenges was reported by Hakimpoor and Arshad (2011). However, despite the fact that Hakimpoor and Arsha (2011) covered 124 papers on ANN models, no application of ANN in predicting port productivity and berth effectiveness in developing economy was reported. Thus, there is a need to bridge this knowledge gap in order to aid shipping business operations in the region. This further necessitates the need for the current study which investigates the use of backpropagation ANN and ARIMA models as predictive models for seaport productivity and berth effectiveness.

Currently, there are studies which have predicted the relationships among profitability, productivity, price recovery, but in different environments. Phusavat and Aneksitthisin (2000) developed a regression equation for predicting profitability while Anyaeche and Ighravwe (2013) compared the performance of 
ANN and regression models when predicting profitability. Another related study is that of Stanivuk and Tokic (2012), which deals with cargo handling time prediction in Croatia seaport. In Stanivuk and Tokic (2012), ANN and ARIMA models were not considered.

\section{A Review of ANN and ARIMA Applications}

Due to the wide application of the ANN, Hakimpoor \& Arshad (2011) presented a review of ANN in aiding management decision-making processes. They reported that the applications of ANN models have covered different business operations such as marketing and sales, finance and accounting, manufacturing and production as well as strategic management and business policy. An investigation of the use of three-layer back-propagation ANN model in addressing service restoration problem in a distribution system was conducted by Kumar et al. (2011). Kumar et al. (2011) observed that ANN has the potential of generating satisfactory results but pointed out that there is a need for such models to be trained with noisy input data set.

Bretas and Phadke (2003) illustrated the importance of using ANN models in power system restoration plan. They observed that the ANN models have high processing speed and generalisation capability when compared with mathematical programming technique and rule-based expert systems. Moradi and Zulkernine (2004) analysed the ability of three layers and a four-layers multi-layer ANN in modelling intrusion detection and classification of attack on computer systems and concluded that the four-layers multi-layer perceptron is a better predictor. Rastegari et al. (2009) studied the application of feed-forward ANN in developing an intrusion system for detecting denial of service attacks against a domain name system. Rastegari et al. (2009) were able to establish the superior performance of feed-forward over statistical pre-processor. A similar superior performance was experienced by Cao and Schniederjans (2006), during the application ANN in designing a model for product and service system selection for an e-tourism system.

Ahmad et al. (2008) compared a resilient back-propagation ANN model with other types of ANN models when designing a model for probing attack detection. They concluded that a resilient back-propagation ANN model performed better than other ANN models that their study considered. Zepka et al. (2009) predicted cloud-to-ground lightning system using multi-layer feed forward ANN model and concluded that the ANN is a useful tool for efficient lightning system construction. Blackard and Dean (1999), also, reported a superior performance of ANN models. Their study compared ANN models performance with that of discriminant analysis when forecasting cover types from cartographic variables. Stanivuk and Tokic (2012) pointed out that the decision-making processes in healthcare management can be enhanced through the use of ANN. This conclusion was arrived at after developing a robust decision support system for healthcare management using the ANN model.

$\mathrm{Wu}$ et al. (2011) predicted the performance characteristic of a reversibly-used cooling tower (RUCT) using back-propagation ANN models. A heat pump heating system in winter under crossflow condition was considered. They observed that the ANN models results were close to experimental values. Kamruzzaman and Sarker (2003) investigated long-term forex rates forecasting using ANN models and ARIMA. They observed that ANN models performed better than an ARIMA $(1,0,1)$ model under a long-term condition. Merh et al. (2010) investigated the performance of ANN and ARIMA when forecasting stock trend. Their study noticed that an ANN enhanced with ARIMA will yield a superior forecasting result than either ANN or ARIMA. Sowell (1992) pointed out that for a long-run gross national product behaviour determination, fractional ARIMA models are robust tools than non-fractional ARIMA models.

Paul et al. (2013) used mean absolute percentage error, absolute mean error, root mean square error, Akaike information criterion, corrected Akaike information criterion and Schwaetz information criterion to select and test different ARIMA models when predicting the average daily price index of pharmaceutical companies in Bangladesh. They observed that the optimal ARIMA model for average daily price 
index was 2, 1, 2. Nanthakumar and Ibrahim (2010) demonstrated the suitability of ARIMA models as a predictive model for predicting the number of tourist arrival in Malaysia. In their study, three different ARIMA models considered and they observed that an ARIMA $(1,0,1)$ was the best model for the number of tourist arrival prediction in Malaysia.

Sarpong (2003) used an ARIMA $(1,0,2)$ to predict maternal mortality. Their model had a percentage error of $3.78 \%$. Felipe et al. (2012) demonstrated the application of ARIMA as a prediction model for soybean prices in the North of Parana. Their work revealed that an ARIMA $(5,0,0)$ was a more realistic model for accomplishing soybean prices prediction. Tse (1997) proposed the use of ARIMA $(2,1,1)$ for modelling office and industrial real-estate prices in Hong Kong, after observing the behaviours of ARIMA models in tracking market prices variation resulting from mass psychology.

Contreras et al. (2003) developed two ARIMA models for electricity price forecasting. After comparing the results obtained with ANN. They concluded that ARIMA models have high potentials to produce minimal forecasting error when compared to ANN models. Li and Moller (2009) presented a comparative analysis of a general linear forecasting model and ARIMA. These models were used to predict monthly temperature. Based on their findings, they observed that the ARIMA model results outperformed that of a general linear forecasting model. Lee et al. (2012) presented a study that demonstrated how ARIMA can be used to predict air pollution index, and the results obtained showed that ARIMA application in air population control will enhance air pollution monitoring.

From the above review, it can be inferred that there exist wide applications of ANN and ARIMA in service systems. Yet, there exist sparse information on ANN and ARIMA applications in predicting seaport productivity and berth effectiveness.

\section{Theory}

\subsection{Artificial neural network}

The ANN model is a computation intelligence tool that was developed for solving problems such as optimisation, mapping, pattern recognition and prediction problems. The fundamental principle of ANN lies in weight adjustment which represents synapse in natural neurons. Weights are combined with input signals in generating outputs in an adjacent layer. This can be achieved with rather a summation or a product rules (Eq. (1)),

$$
\text { Net }=\sum_{i=1}^{n} w_{i}^{g} x_{i} \text {. }
$$

The combination of neuron values and connecting weights with bias is used in generating succeeding neuron values with the aid of transfer functions (Eq. (2)). Eq. (2) represents such a sigmoid transfer function (Engelbrecht, 2007).

$$
\text { Sig }=\frac{1}{1+\exp ^{-\left(\mathrm{Net}_{i}+\theta_{i}\right)}} \text {. }
$$

During training of an ANN model, an error function is used to adjust the weights in an ANN model. Such errors are obtained using Equation (3): the difference between actual and predicted values that are generated by an ANN model. Weight adjustment is either carried out either on-line or off-line. Online weights adjustment is carried out after each pattern has been fed into an ANN model, while off-line weights adjustment requires weights update after all the patterns have been fed into an ANN model. To update a weight, Eq. (4) is considered.

$$
\begin{aligned}
& \varepsilon_{i}^{g}=A_{i}-f_{i}, \\
& W_{i}^{g}=W_{i}^{g-1}+\alpha \varepsilon_{i}^{g} x_{i} .
\end{aligned}
$$


The structure of a multi-layer perceptron of the ANN used in this study is depicted in Fig. 1, while the algorithm for training this network is presented as Algorithm 1. Usually, after each epoch, the performance of an ANN model is evaluated using statistical measures - mean square error (MSE), mean absolute error, coefficient of correlation $\left(\mathrm{R}^{2}\right)$ and mean percentage error. In this study, MSE (Eq. 5) and $\mathrm{R}^{2}$ (Equation 6) are used to evaluate the performance of the developed ANN model.

$$
\begin{aligned}
& M S E=\frac{\sum_{i=1}^{m}\left(A_{i}-F_{i}\right)^{2}}{m}, \\
& R^{2}=1-\frac{\sum_{i=1}^{m}\left(A_{i}-F_{i}\right)^{2}}{\sum_{i=1}^{m} F_{i}^{2}},
\end{aligned}
$$

where $A_{i}$ is the actual value of pattern $i$, and $F_{i}$ is predicted a value of pattern $i$.

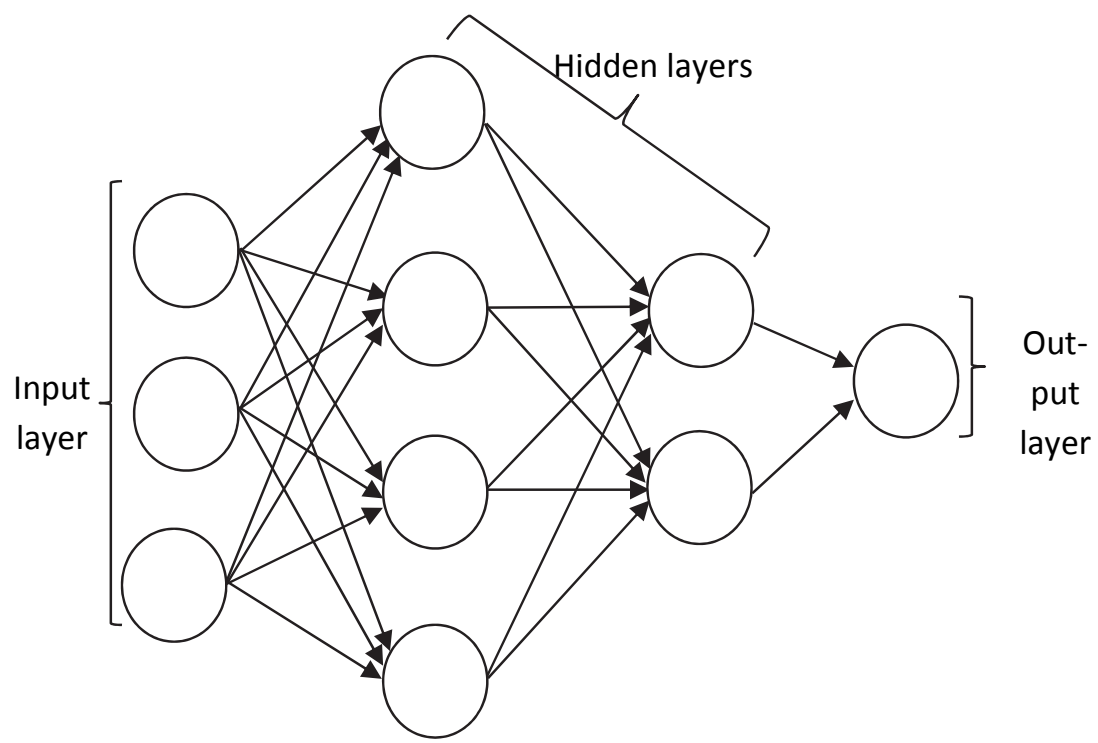

\section{Algorithm 1}

Fig. 1. Four layer ANN architecture

A multi-layer perceptron ANN

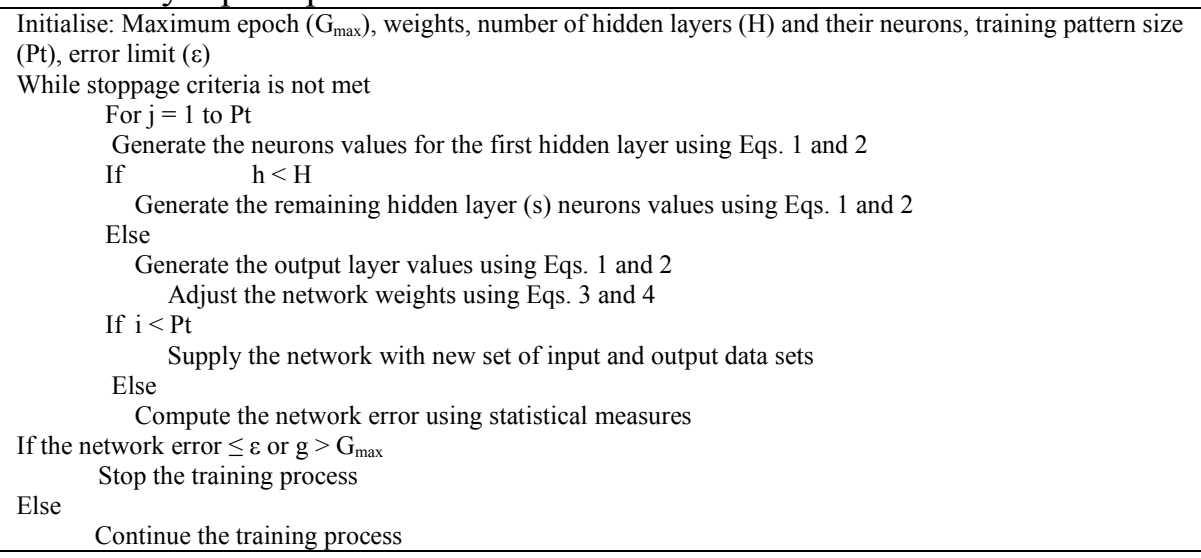

\subsection{Autoregression Integrated Moving Average}

ARIMA is an advanced time series model which combines three series - autoregressive order (p), integrated difference order $(\mathrm{d})$ and moving average $(\mathrm{q})$ in forecasting dependent parameter. Its ARIMA 
model to predict dependent parameters without much emphasis on historical data pattern is responsible for ARIMA model wide applications in literature especially in financial journals (Tse, 1997). The formula for computing $\mathrm{p}$ is expressed as Eq. (7).

$$
z_{t}=\beta_{0}+\beta_{1} z_{t-1}+\ldots+\beta_{p} z_{t-p}+\varepsilon_{t}
$$

where $\varepsilon_{\mathrm{t}}$ is random error and $\mathrm{z}_{\mathrm{t}}$ stands for stationary time series at time $\mathrm{t}$. The moving average (q) aspect of ARIMA model (Bhardwaj, 2015) is expressed as Eq. (8).

$$
z_{t}=\mu+\varepsilon_{t}-\alpha_{1} \varepsilon_{t-1}-\ldots-\alpha_{p} z_{t-p}
$$

where $\mu$ is constant mean of a process, $\alpha_{p}$ and $\beta_{p}$ are coefficient and $\varepsilon_{t}$ is error term at time $\mathrm{t}$ (Bhardwaj, 2015). According to Nochai and Nochai (2006), the combination of Eq. (7) and Eq. (8) represent the formula for ARMA model (Eq. (9)).

$$
z_{t}=\beta_{0}+\beta_{1} z_{t-1}+\ldots+\beta_{p} z_{t-p}-\alpha_{1} \theta_{t-1}-\ldots-\alpha_{q} \theta_{t-q}+\varepsilon_{t}
$$

The integrated difference (d) for $\mathrm{Z}_{\mathrm{t}}$ is expressed as Equation (10), this gives the interrelationships among $\mathrm{Z}_{\mathrm{t}}, \mathrm{B}, \mathrm{d}$ and $\mathrm{y}_{\mathrm{t}}$.

$$
y_{t}=(1+B)^{d} Z_{t} \text {, }
$$

where B is called backshift operator, and (1-B) is called differencing operator (Meyler et al., 1998). The general form of ARIMA is expressed as Eq. (11).

$$
\beta_{p}(B) y_{t}=\mu+\alpha_{q}(B) \varepsilon_{t} .
$$

To apply ARIMA models, the following steps are required: data collection and examination, determination of the stationarity of a time series, model identification and estimation, diagnostic checking, forecasting and forecast evaluation (Meyler et al., 1998).

\section{Results and Discussion}

\subsection{Model Application}

The application of the ANN model described in the previous section is demonstrated in this section. Realworld data collected from Apapa port in Lagos, Nigeria (Stephens, 2012) were used for the analysis. Inputs for the ANN models are days ship spent at a port $\left(x_{1}\right)$, days at berth $\left(x_{2}\right)$ and tonnage handled by $\operatorname{ship}\left(x_{3}\right)$; the ANN model outputs are port productivity (PP) and berth effectiveness (BE). Since proper training of ANN models requires large data sets, Bootstrap sampling approach was used to generate additional 70 data-tuple; this sampling approach is based on sampling by replacement. And the values obtained for $x_{1} x_{2}$ and $x_{3}$ were used to generate each data-tuple output values - see Eqs. (12-13) (Stephens, 2012).

$$
\begin{aligned}
& \text { Port productive }(\mathrm{PP})=\frac{x_{3}}{x_{1}} \\
& \text { Berth effectiveness }(\mathrm{BE})=\frac{x_{3}}{x_{2}}
\end{aligned}
$$

The algorithm described in section 2 was coded in VB.Net software (2012) programming language on a computer with $2.00 \mathrm{~Hz}$ processor, $2.00 \mathrm{~GB}$ installed memory (RAM) on Windows 7 Ultimate. The parameters settings in Table 1 . MSE and $\mathrm{R}^{2}$ are used to evaluate the ANN model's performance during training (Figures 2 and 3). After training the ANN model, its performance was tested using the testing datasets (Fig. 4 and Fig. 5). It should be noted that the epoch in Figures 2 to 5 are on scale 1:100. 
Table 1

Parameter Settings

\begin{tabular}{lc}
\hline Parameters & Values \\
\hline Learning rate & 0.3 \\
Epoch & 10000 \\
Training tolerance & 0.001 \\
Training data size & 60 \\
Testing data size & 20 \\
Hidden layer 1 & 5 \\
Hidden layer 2 & 7 \\
Transfer function & Sigmoid function \\
\hline
\end{tabular}

The ARIMA model used in this study was implemented using STATA 11 software, the values of $p, d$, and $q$ were obtained with time series graphs (correlogram, partial correlogram, and line plots). The ARIMA model obtained for port productivity was $(1,0,4)$, while berth effectiveness was $(1,0,4)$. Since the integrated difference $(d)$ is zero, the required equation for the port productivity and the berth effectiveness predictive models was Equation (10). It should be noted that our decision is based on datasets considered and deviation may be observed when data from another port is used in generating values for $p, d$, and $q$. The predictive models that were developed were used in forecasting 20 data points that were set aside as testing data. A comparative analysis of the ANN and ARIMA models performance was carried out and the results as shown in Figures 2 to 5 and in Table 2.

\subsection{Discussion of Results}

The performance of the MLP-ANN (3-5-7-2) model used in this study showed that it has the potential of mapping input data into outputs data for the case study. The MLP-ANN model becomes more stable as the number of epoch increases. The results presented in Fig. 2 to Fig. 3 showed that there is slight fluctuation in the differences between actual and predicted values of the port productivity and the berth effectiveness. These results showed that MSE and $\mathrm{R}^{2}$ fluctuate slightly as the model moves from one epoch to another. Since this does not affect the quality of the solution obtained significantly, there was no need to change the training algorithm during the development of the ANN model. However, in a case where a model's performance degrade from one epoch to another, other algorithms such as scaled conjugated gradient could be used to substitute gradient descent algorithm (Kamruzzaman et al., 2006).

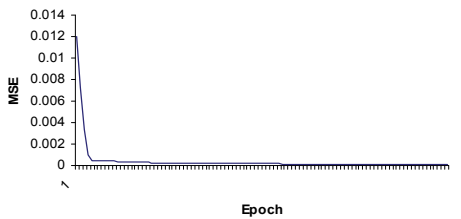

(A) MSE for port productivity

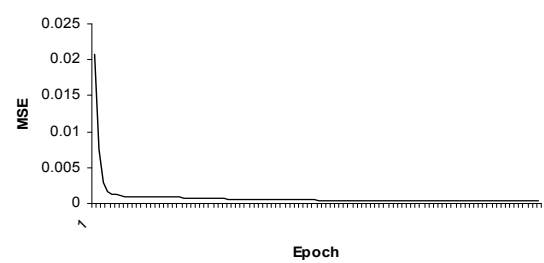

(B) MSE for berth effectiveness

Fig. 2. The ANN model's MSE results during training

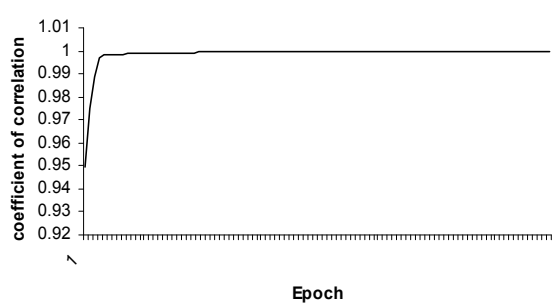

(A) $\mathbf{R}^{2}$ for port productivity

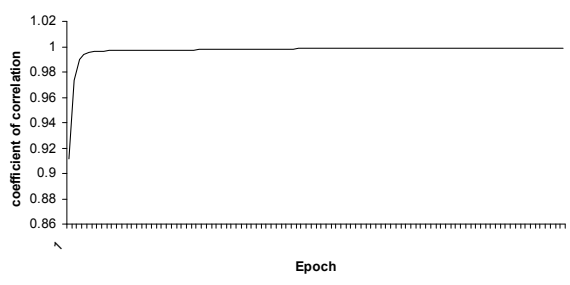

(B) $\mathbf{R}^{2}$ for berth effectiveness

Fig. 3. The ANN model's $R^{2}$ results during training 


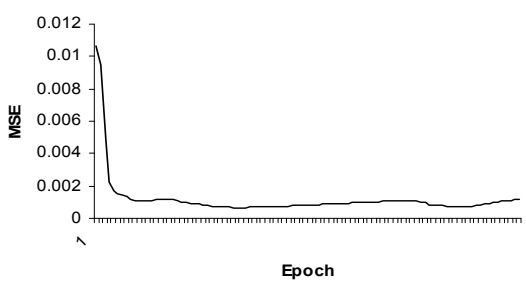

(A) MSE for port productivity

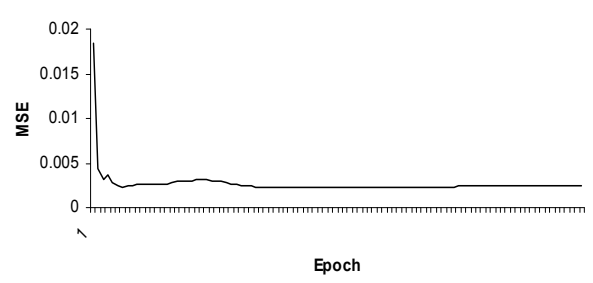

(B) MSE for berth effectiveness

Fig. 4. The ANN model's MSE results during testing
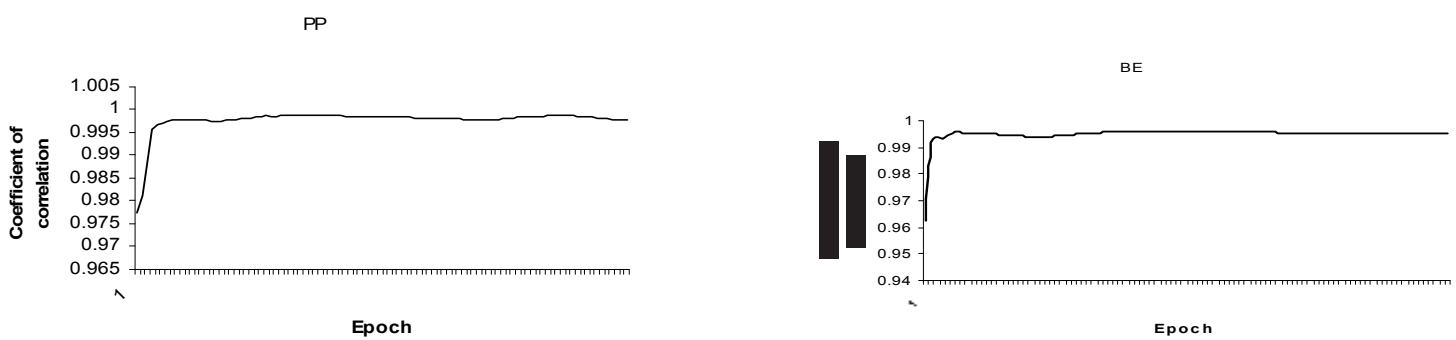

\section{(A) $\mathbf{R}^{2}$ for port productivity}

\section{(B) $\mathbf{R}^{2}$ for berth effectiveness}

Fig. 5. The ANN model's $\mathrm{R}^{2}$ results during testing

The ARIMA models also performed satisfactorily, especially when used to predict the berth effectiveness of Apapa port. The ARIMA's berth effectiveness MSE result showed that it is approximately $9 \%$ better than that of the MLP-ANN model. Further investigation revealed that the value of $\mathrm{R}^{2}(0.998)$ obtained from the MLP-ANN model for berth effectiveness prediction yielded better results that of ARIMA model result (Table 2). The MLP-ANN results (i.e., MSE and $\mathrm{R}^{2}$ ) for port productivity were better than that of the ARIMA model. From the above discussion, it could be inferred statistically that, the MLP-ANN is a better predictive tool than ARIMA for the current application.

Table 2

MSE and Correlation Coefficient using ARIMA Model

\begin{tabular}{lll}
\hline Port Measures & MSE & $\mathrm{R}^{2}$ \\
\hline Port productivity & 0.0038 & 0.9862 \\
Berth effectiveness & 0.0021 & 0.9928 \\
\hline
\end{tabular}

\section{Conclusions}

This study has successfully investigated the performance of MLP-ANN and ARIMA models used to predict seaport productivity and berth effective. These models performances were studied using mean square error and coefficient of correlation as performance measures, for instance, when predicted values from MLP-ANN and ARIMA were compared with the target values during model testing, it was observed the MLP-ANN model produced a better line of fit than the ARIMA models. This finding is consistent with those of $\mathrm{Wu}$ (2011) and Kamruzzaman and Sarker (2003), which compared MLP-ANN and ARIMA in different environments. With this result, it could be said that investors can use ANN model to predict the performance of their investment in Nigeria shipping business.

In addition, this finding will open up the possibility of using the ANN models to predict the performance of other, (agriculture, telecommunication, and power generation) in Nigeria. Despite the good performance of the ANN model, researchers can pursue a further study that will look at fine-tuning the quality of solution obtained from the ANN model using other artificial intelligence tools such as differential 
evolution, bat algorithm, and particle swarm optimisation. Adding to this research gap, the proposed methodology can be used to study the productivity of other service systems.

\section{References}

Ahmad, I., Abdullah, A.B., \& Alghamdi, A.S. (2009). Application of artificial neural network in detection of probing attacks. IEEE Symposium on Industrial Electronics and Applications, October 4-6, Kuala Lumpur, Malaysia, 557-562.

Anyaeche, C.O., \& Ighravwe, D.E. (2013). Predicting performance measures using linear regression and neural network: A comparison. African Journal of Engineering Research, 1(3), 84-89.

Bhardwaj, S.P. (2015). Market intelligence and price forecast. Retrieved April, 12, 2015, from www.iasri.res.in/cbp/data.

Blackard, J.A., \& Dean, D.J. (1999). Comparative accuracies of artificial neural networks and discriminant analysis in predicting forest cover types from cartographic variables. Computers and Electronics in Agriculture, 24, 131-151.

Bretas, A.S., \& Phadke, A.G. (2003). Artificial neural networks in power system restoration. IEEE Transactions on Power Delivery, 18(4), 1181-1186.

Cao, Q., \& Schniederjans, M.J. (2006). Agent-mediated architecture for reputation-based electronic tourism systems: A neural network approach. Information \& Management, 43, 598-606.

Contreras, J., Espinola, R., Nogales, F.J., \& Conejo, A.J. (2003). ARIMA Models to Predict next-Day Electricity Prices. IEEE Transactions on Power Systems, 18(3), 1014-1020.

Engelbrecht, A.P. (2007). Computational Intelligence: An Introduction. John Wiley and Son Ltd.

Felipe, I.J.d-S, Mol, A.L.R., \& e-Almeida, V.d-S. (2012). Application of ARIMA models in soybean series of prices in the north of Parana.Custos e @gronegócio on line, 8, 78-91.

Hakimpoor, H., \& Arshad, K.A.B. (2011). Artificial neural networks' applications in management. World Applied Sciences Journal, 14 (7), 1008-1019.

Indraratna, B., Rujikiatkamjorn, C., Geng, X., Ameratunga, J., \& Boyle, P. (2011). Performance and prediction of vacuum combined surcharge consolidation at port of Brisbane, Coastal and Marine Geotechnics: Foundations for Trade, Sydney: Australia, 45-60.

Kamruzzaman, J., Sarker, R.A., \& Begg, R. (2006). Artificial neural networks: Applications in finance and manufacturing, In Kamruzzaman J., Begg R. and Sarker R.A. (Eds.). Artificial neural networks: Applications in finance and manufacturing, Idea Group publishing, London.

Kamruzzaman, J., \& Sarker, R.A. (2003). Comparing ANN based models with ARIMA for prediction of forex rates. ASOR Bulletin, 22(2), 1-10.

Kumar, Y., Das, B., \& Sharma, J. (2011). Application of ANN in service restoration in distribution systems with noisy input. IPCSIT, 7, 247-252.

Lee, M.H., Abd. Rahman, N.H., Suhartono, Latif, M.T., Nor, M.E., \& Kamisan N.A.B. (2012). Seasonal ARIMA for forecasting air pollution index: A Case Study. American Journal of Applied Sciences, 9(4), 570-578.

Li, X., \& Moller, M. (2009). Applying GLM model and ARIMA model to the analysis of monthly temperature of Stockholm. Department of Economics and Society, Dalarna University, 1-24.

Merh, N., Saxena, V.P., \& Pardasani K.R. (2010). A comparison between hybrid approaches of ANN and ARIMA for Indian stock trend forecasting. Business Intelligence Journal, 3(2), 23 - 43.

Meyler, A., Kenny, G., \& Quinn, T. (1998). Forecasting Irish inflation using ARIMA models economic Analysis. Research And Publications Department, Central Bank of Ireland.

Moradi, M., \& Zulkernine, M., (2004). A neural network based system for intrusion detection and classification of attack. International Conference on Advance in Intelligence Systems, Theory and Applications, Luxembourg, Kirchberg, Luxembourg, IEEE, 148-153.

Nanthakumar, L., \& Ibrahim, Y. (2010). Forecasting international tourism demand in Malaysia using Box Jenkins SARIMA application. South Asian Journal of Tourism and Heritage, 3(2), 50-60.

Nochai, R., \& Nochai, T. (2006). ARIMA model for forecasting oil palm price. Proceedings of 2 nd IMTGT Regional Conference on Mathematics, Statistics and Applications, Universiti Sains Malaysia, Penang, June 13-15, 1-7. 
Nze, O.N. (2011). Assessment of the Productivity of the Nigerian Shipping Industry. An unpublished M.Sc. thesis, submitted to the Transport Management Technology Department, Federal University of Technology, Owerri.

Odularu, G.O. (2008). Crude oil and the Nigerian economic performance. Oil and Gas Business, 1-27.

Phusavat, K., \& Aneksitthisin, E. (2000). Interrelationship among profitability, productivity and price recovery: Lessons learned from a wood-furniture company. In Proceedings of Industrial Engineering Network, Petchaburi, Thailand.

Paul, J.B., Hoque, M.S., \& Rahman, M.M. (2013). Selection of best ARIMA model for forecasting average daily share price index of pharmaceutical companies in Bangladesh: A case study on square pharmaceutical Ltd. Global Journal of Management and Business Research Finance, 13(3), 14 -26.

Rastegari, S., Saripan, M.I., \& Rasid, M.F.A. (2009). Detection of denial of service attacks against domain name system using neural networks. International Journal of Computer Science Issues, 6(1), 2327.

Sarpong, S.A. (2013). Modelling and forecasting maternal mortality: An application of ARIMA models. International Journal of Applied Science and Technology, 3(1), 19-28.

Sowell, F. (1992). Modelling long-run behaviour with the fractional ARIMA model. Journal of Monetary Economics, 29, 277-302.

Stephens, M.S., Stephens, O., Nze, O., Ibe, C.C., \& Ukpere, W.I. (2012). An assessment of the productivity of the Nigerian shipping industry using Saari productivity model. African Journal of Business Management, 6(15), 5414-5432.

Stanivuk, T., \& Tokic, T. (2012). How to predict cargo handling times at the sea port affected by weather conditions. Croatian Operational Research Review (CRORR), 3, 103-112.

Tse, R.Y.C. (1997). An application of the ARIMA model to real-estate prices in Hong Kong. Journal of Property Finance, 8(2), 152-163.

World port source (WPS). Home site. Retrieved September 26, 2014, from $\mathrm{http} / /$ :www.worldportsource.com.

Wu, J., Zhang, G., Zhang, Q., Zhou, J., \& Wang, Y. (2011). Artificial neural network analysis of the performance characteristics of a reversibly used cooling tower under cross flow conditions for heat pump heating system in winter. Energy and Buildings, 43, 1685-1693.

Zemguliene, J. (2009). Productivity in the service sector: A service classification scheme for productivity measurement. Ekonomika, 86, 81-88.

Zepka, G.d-S., Pinto Jr., O, Farias, W.R.G., Carretero, M.A., \& Carneiro, J.C. (2008). A forecast cloudto-ground lightning system based on neural network-preliminary results. 20th International Lightning Detection Conference, 21-23 April, Tucson, Arizona, USA.

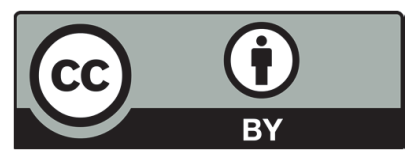

(C) 2018 by the authors; licensee Growing Science, Canada. This is an open access article distributed under the terms and conditions of the Creative Commons Attribution (CCBY) license (http://creativecommons.org/licenses/by/4.0/). 